\title{
Cost-effectiveness of inhaled oxytocin for prevention of postpartum haemorrhage: a modelling study applied to two high burden settings
}

Natalie Carvalho ${ }^{1 *}$, Mohammad Enamul Hoque ${ }^{2}$, Victoria L. Oliver ${ }^{3}$, Abbey Byrne $^{3}$, Michelle Kermode ${ }^{4}$, Pete Lambert ${ }^{3}$, Michelle P. Mclntosh ${ }^{3}$ and Alison Morgan ${ }^{4}$

\begin{abstract}
Background: Access to oxytocin for prevention of postpartum haemorrhage (PPH) in resource-poor settings is limited by the requirement for a consistent cold chain and for a skilled attendant to administer the injection. To overcome these barriers, heat-stable, non-injectable formulations of oxytocin are under development, including oxytocin for inhalation. This study modelled the cost-effectiveness of an inhaled oxytocin product $(\mathrm{IHO})$ in Bangladesh and Ethiopia.

Methods: A decision analytic model was developed to assess the cost-effectiveness of $\mathrm{HO}$ for the prevention of PPH compared to the standard of care in Bangladesh and Ethiopia. In Bangladesh, introduction of $\mathrm{IHO}$ was modelled in all public facilities and home deliveries with or without a skilled attendant. In Ethiopia, IHO was modelled in all public facilities and home deliveries with health extension workers. Costs (costs of introduction, PPH prevention and PPH treatment) and effects (PPH cases averted, deaths averted) were modelled over a 12-month program. Life years gained were modelled over a lifetime horizon (discounted at 3\%). Cost of maintaining the cold chain or effects of compromised oxytocin quality (in the absence of a cold chain) were not modelled.

Results: In Bangladesh, $1 \mathrm{HO}$ was estimated to avert 18,644 cases of PPH, 76 maternal deaths and 1954 maternal life years lost. This also yielded a cost-saving, with the majority of gains occurring among home deliveries where $\mathrm{IHO}$ would replace misoprostol. In Ethiopia, IHO averted 3111 PPH cases, 30 maternal deaths and 767 maternal life years lost. The full IHO introduction program bears an incremental cost-effectiveness ratio (ICER) of between 2 and 3 times the per-capita Gross Domestic Product (GDP) (\$1880 USD per maternal life year lost) and thus is unlikely to be considered cost-effective in Ethiopia. However, the ICER of routine $\mathrm{HO}$ administration considering recurring cost alone falls under 25\% of per-capita GDP (\$175 USD per maternal life-year saved).

\footnotetext{
* Correspondence: natalie.carvalho@unimelb.edu.au

${ }^{1}$ Centre for Health Policy \& Global Burden of Disease Group, School of

Population and Global Health, The University of Melbourne, Melbourne, VIC 3010, Australia

Full list of author information is available at the end of the article
}

(c) The Author(s). 2020 Open Access This article is licensed under a Creative Commons Attribution 4.0 International License, which permits use, sharing, adaptation, distribution and reproduction in any medium or format, as long as you give appropriate credit to the original author(s) and the source, provide a link to the Creative Commons licence, and indicate if changes were made. The images or other third party material in this article are included in the article's Creative Commons licence, unless indicated otherwise in a credit line to the material. If material is not included in the article's Creative Commons licence and your intended use is not permitted by statutory regulation or exceeds the permitted use, you will need to obtain permission directly from the copyright holder. To view a copy of this licence, visit http://creativecommons.org/licenses/by/4.0/. The Creative Commons Public Domain Dedication waiver (http://creativecommons.org/publicdomain/zero/1.0/) applies to the data made available in this article, unless otherwise stated in a credit line to the data. 
(Continued from previous page)

Conclusions: $\mathrm{HO}$ has the potential to expand access to uterotonics and reduce PPH-associated morbidity and mortality in high burden settings. This can facilitate reduced spending on PPH management, making the product highly cost-effective in settings where coverage of institutional delivery is lagging.

Keywords: Maternal health, Global health, Sustainable development goals, Heat-stable uterotonics, Health economic analysis, Ethiopia, Bangladesh

\section{Introduction}

Despite substantial global progress in reducing maternal mortality over the last two decades, more than a quarter of a million women still die each year as a result of pregnancyor delivery-related complications $[1,2]$. Postpartum haemorrhage (PPH), defined as blood loss of $500 \mathrm{ml}$ or more within $24 \mathrm{~h}$ of childbirth, is responsible for one fifth of all maternal deaths and is the leading cause of maternal mortality globally [3]. The World Health Organization (WHO) recommends oxytocin (10 IU) delivered intravenously or intramuscularly to prevent PPH [3].

Injectable oxytocin requires cold chain storage to prevent degradation and to be administered parenterally: two considerations that limit effective utilisation in many lowand middle-income countries (LMICs). Maintenance of a consistent cold chain in LMICs is challenged by resource and infrastructure constraints, and consequently, the quality of oxytocin in these settings is often below international quality specifications [4]. Further, workforce shortages and policies that prohibit administration of injections by some cadres of peripheral health workers limit access to oxytocin for many women in LMICs [5-7]. In settings where skilled health personnel are not available to administer injectable uterotonics, WHO recommends the oral or sublingual administration of misoprostol by community health workers [3]. However, misoprostol is less effective than oxytocin in preventing $\mathrm{PPH}$ and is associated with a greater number of side effects [8].

Novel formulations of oxytocin are under development, which aim to be heat-stable and delivered without injection, including a sublingual tablet [9] and drypowder inhalers $[10,11]$. Subject to clinical testing, these products have the potential to deliver clinical protection against $\mathrm{PPH}$ without reductions in efficacy that result from inconsistencies in cold chain supply and storage. As non-injectable options for oxytocin administration, these products may facilitate task-shifting to lower tier health workers who may not be able or authorised to deliver an injection. In settings with enabling policy environments and supportive health system structures, these products may be suitable for self-administration through an advanced community distribution model, which has been explored with misoprostol in several countries [12].

Evidence on the expected health gains, costs, and costeffectiveness of a heat-stable, non-injectable oxytocin product is essential for national-level policy-makers, external donors and development partners working towards reducing maternal mortality. The objective of this study was to estimate the potential impact, costs, and cost-effectiveness of introducing an inhaled oxytocin product (IHO) in two high-burden countries: Bangladesh and Ethiopia. These countries were selected based on several considerations including their high burden of $\mathrm{PPH}$ and the accessibility of costing and health data through the networks of the authors. With differing levels of maternal mortality, and unique policy environments leading to important distinctions in delivery location and uterotonic coverage, these countries represent ideal case studies for considering the expected outcomes following implementation of IHO more globally.

\section{Methods \\ Model overview}

A decision analytic model (Fig. 1) was built in Excel (version 16.22) to model the introduction of IHO for the prevention of $\mathrm{PPH}$ compared to the status quo in Bangladesh and Ethiopia. For each country, the cohort of women who would experience a birth during a 1-year period is run through the model, going either down the usual care pathway (status quo) or down the intervention pathway (IHO used as uterotonic).

The status quo and intervention scenarios were modelled based on the current service delivery structures and policy contexts in both countries (outlined in Table 1), and take into account the current use of uterotonics within and outside of facilities. To this end, we defined five settings of childbirth and modelled the inhaled oxytocin product to replace the uterotonics used in the status quo (injectable oxytocin or misoprostol) depending on the delivery setting (Table 2). In Bangladesh, introduction of IHO was modelled in all public facilities and at home deliveries with or without a skilled birth attendant (settings 1-4). In Ethiopia, introduction of IHO was modelled in all public facilities and at home deliveries that are attended by HEWs (settings 1-3). These introduction settings for $\mathrm{IHO}$ have been designed to align with existing policy in each country relating to the settings where uterotonic use for $\mathrm{PPH}$ prevention is authorised. 


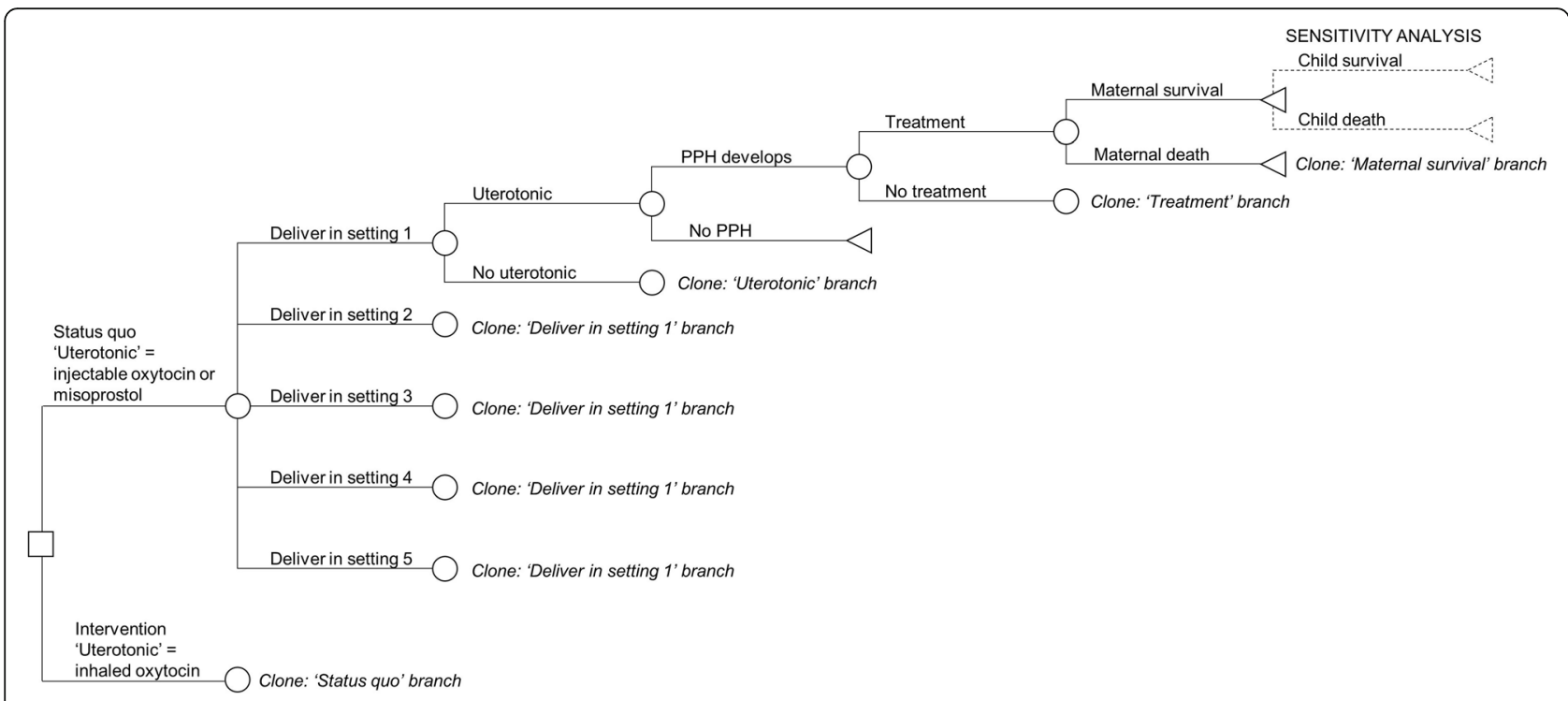

Fig. 1 Decision tree for outcomes over a single year, depicting use of inhaled oxytocin versus current uterotonics

We estimated the costs and cost-effectiveness of IHO from a limited societal perspective, including both health system, household direct medical costs and household non-medical costs related to transport and other deliveryrelated expenses. Indirect costs due to lost productivity were not modelled. The effectiveness of each uterotonic is calculated based on the coverage at each delivery setting and the efficacy of the drug.

Model outcomes include intermediate clinical events (non-severe PPH, defined as 500-1000-ml blood loss, and severe $\mathrm{PPH}$, defined as blood loss $>1000 \mathrm{ml}$ ) and long-term outcomes (PPH-related maternal death, maternal death-related child deaths and life years lost). A 1year program intervention was modelled, with all costs occurring in the first year, and health benefits modelled over a life-time horizon. Future costs in added life-years were not included, but future health outcomes were discounted at $3 \%$ in line with previous economic evaluations in Bangladesh and Ethiopia that have applied a discount rate to benefits [21-23]. The discount rate was varied from 0 to $6 \%$ as part of a sensitivity analysis.

Model parameters were informed by the published literature supplemented by in-country interviews to collect local costing data. All costs were adjusted to 2017 US dollars (USD) using country-specific consumer price indices and exchange rates of 80.65 Bangladeshi Taka and 21.73 Ethiopian Birr per USD. Opportunity costs of non-tradable goods taken from other study settings were converted using purchasing power parity. Sensitivity analyses were conducted to determine the robustness of findings to changes in input parameters. In the base case analysis, only health outcomes for the woman were considered, with long-term outcomes for the child modelled in sensitivity analyses.
Incremental cost-effectiveness ratios (ICERs) of IHO introduction, compared to the current use of injectable oxytocin or misoprostol, were calculated in terms of cost per case of PPH avoided, cost per maternal death averted and cost per life year saved. We did not have a reliable way to estimate disability-adjusted life years averted given that the duration of disability (the leading associated disability being anaemia) following a PPH is not well known, and anaemia is often a common preexisting condition, particularly in Bangladesh [24]. Gross domestic product (GDP) per capita has historically been used as a threshold for determining the costeffectiveness of an intervention in LMICs, with an intervention categorised as cost-effective if the ICER (expressed as \$ per life year saved, or health-adjusted life year saved) falls below $3 \times \mathrm{GDP} /$ capita and very cost-effective if the ICER falls below $1 \times$ GDP/capita [25]. Recent guidance, however, indicates these thresholds are likely to be too high, and much lower thresholds may be more in line with real willingness-to-pay, particularly in LMICs [26]. Recently estimated thresholds for Bangladesh and Ethiopia range from 2 to $50 \%$ of GDP/capita [26]. As such, ICERs were compared to several thresholds: $0.25 \times, 0.5 \times$, and $1 \times$ GDP/capita, using Bangladesh's GDP/capita of US\$1516 (2017) and Ethiopia's GDP/capita of US\$768 (2017).

We followed the Consolidated Health Economic Evaluation Reporting Standards guidelines in reporting our findings [27].

All parameters are detailed in the following sections, tables and the appendix (Additional file 1) [13, 16, 17, 28-33], and the model is available to researchers upon request. 
Table 1 Country health system contexts

\begin{abstract}
Bangladesh
Located in South Asia, Bangladesh is the third most populous country in the region and one of the most densely populated countries in the world. A recent national survey reported the maternal mortality ratio in Bangladesh to be 196 deaths per 100,000 live births in 2016, with 31\% due to haemorrhage (antepartum and postpartum) [13]. The public service delivery structure includes national, district, upazilla (sub-district), union and ward levels [14]. At the union level, union sub-centres and health and family welfare centres provide the first contact between the population and the health care system and a minority of these facilities offer normal delivery services [15]. At the upazilla level, maternal and child welfare centres and upazilla health complexes typically offer normal delivery services and some are equipped to provide caesarean section. Approximately one third of deliveries occur in a private facility and approximately one half of women give birth outside of a health facility [13]. The Government of Bangladesh has outlined a strategy to scale up misoprostol for the prevention of PPH outside of facilities through an advanced distribution model [16]. A 2015-2016 evaluation showed that community distribution of misoprostol had reached $17 \%$ of all births in Bangladesh at this stage of program roll out [13].
\end{abstract}

\section{Ethiopia}

Ethiopia is located in North-East Africa and, with a population of just over 94 million, it is the second most populous country in Africa. Maternal mortality has decreased substantially in the last decade, and most recent reports estimate a maternal mortality ratio of 422 [17]. The government is the main provider of health care services in the country through a three-tier system consisting of specialist hospitals, general hospitals and primary care units (composed of a network of primary hospitals, health centres and health posts). At the primary care level, emergency obstetric care services are available at some primary hospitals, while health centres provide delivery services and some are equipped to provide basic emergency obstetric care. Each health centre is connected to four health posts, which are staffed by two health extension workers (HEWs). This cadre provide a package of basic curative, promotive and preventative care at the health post or in the home. While national policy in Ethiopia permits use of misoprostol by HEWs, progress towards scale up beyond research areas is uncertain $[18,19]$. The Ministry of Health has introduced integrated refresher in-service training to improve the skills of HEWs and to upgrade these health workers from HEW3 to HEW4 (which includes competencies to support skilled attendance at birth). Despite the conduct of pilot programs to explore the feasibility and acceptability of advanced distribution of misoprostol to pregnant women $[18,20]$, the government of Ethiopia has elected not to adopt this strategy into policy.

\section{Input parameters}

\section{Demography, maternal mortality and incidence of PPH}

The expected number of births among women of reproductive age (15-49 years) by 5-year age group was calculated based on country-specific demographic estimates and country- and age-specific fertility rates (Table 3). The number of maternal deaths and deaths due to PPH were calculated for each 5-year age group based on country- and age-specific maternal mortality ratios and estimated proportions of maternal deaths due to $\mathrm{PPH}$ from country and regional data (Table 3). Deaths unrelated to PPH were assumed to be similar across the status quo and intervention scenarios and were not captured in the model. Number of maternal life years lost was estimated based on the age-specific life expectancy, which was drawn from the WHO Global Health Observatory [39]. A 3\% discount rate was applied to number of life years lost, and this discount rate was varied in a sensitivity analysis. Rates of non-severe (5001000-ml blood loss) and severe PPH (blood loss greater than $1000 \mathrm{ml}$ ) were calculated for each delivery setting based on uterotonic efficacy and coverage.

\section{Efficacy}

The efficacy of injectable oxytocin versus no uterotonic was drawn from a recent Cochrane review (Table 3) [8]. This does not adjust for the possibility that degradation due to inadequate cold storage may result in reduced efficacy from these levels. A 2016 systematic review found an average of $22.3 \%$ and $57.5 \%$ of oxytocin ampoules collected from Asia and Africa respectively contained below international quality specifications [4]. However, the relationship between oxytocin degradation and clinical effect is not well understood. Thus, it is impossible to credibly model a deviation in efficacy for the injectable oxytocin product. This represents a limitation of the study as the model may underestimate the costeffectiveness of IHO. The efficacy of misoprostol compared to no uterotonic was drawn from the same Cochrane review. We modelled inhaled oxytocin to have the same efficacy as injectable oxytocin in line with available clinical data demonstrating the similarity in pharmacokinetic profiles for these two administration routes [11].

\section{Place of delivery}

The percentage of women giving birth in each delivery setting was drawn from national surveys (Table 4). In Ethiopia, there has been a substantial increase in facilitybased births, with the most recent health facility survey data from 2016 indicating that most deliveries (66\%) occur in health facilities [17], compared to findings from the most recent demographic and health survey (DHS), which indicated that only $26 \%$ of births in the preceding 5 years were in facility settings [36]. To allow for extrapolation of these increasing rates of facility deliveries, we modelled $70 \%$ of deliveries to occur in a health facility. We modelled the remaining $30 \%$ of deliveries to be divided between those that are attended by a HEW (4.5\%) and those not attended by a formal provider (25.5\%) based on studies conducted in Amhara and Oromia [18]. This represents a small increase in the proportion of deliveries attended by HEW when compared to 2016 DHS data (1.8\%), which may be a reasonable assumption based on recent programs to upgrade HEW to the level of skilled birth attendant. Sensitivity analyses were conducted to model realistic lower and upperbound estimates of deliveries in facilities (40 to 60\% in Bangladesh and 60 to $80 \%$ in Ethiopia), with the same proportions of deliveries across each out-of-facility and in-facility setting. 
Table 2 Description of delivery settings that were defined for the purpose of modelling uterotonic coverage in status quo and intervention scenarios. The uterotonics used for prevention of PPH (in non-operative deliveries) at each setting in status quo and intervention scenarios are specified

\begin{tabular}{|c|c|c|c|c|c|}
\hline & Setting 1 & Setting 2 & Setting 3 & Setting 4 & Setting 5 \\
\hline & $\begin{array}{l}\text { Tertiary-level public } \\
\text { facilities }\end{array}$ & $\begin{array}{l}\text { Secondary-level public } \\
\text { facilities }\end{array}$ & $\begin{array}{l}\text { Primary health facilities and } \\
\text { non-facility births attended } \\
\text { by a skilled provider }\end{array}$ & $\begin{array}{l}\text { Non-facility births } \\
\text { not attended by } \\
\text { a skilled provider }\end{array}$ & $\begin{array}{l}\text { Private sector } \\
\text { deliveries }\end{array}$ \\
\hline \multicolumn{6}{|c|}{ Settings included in each country } \\
\hline Bangladesh & $\begin{array}{l}\text { Medical Colleges, } \\
\text { Specialised hospitals, } \\
\text { District hospitals }\end{array}$ & $\begin{array}{l}\text { Upazilla health complex, } \\
\text { Maternal and child } \\
\text { welfare centres }\end{array}$ & $\begin{array}{l}\text { Union sub-centres, } \\
\text { Rural sub-centres, Union } \\
\text { health and family welfare } \\
\text { centres, Community clinics, } \\
\text { out-of-facility deliveries } \\
\text { attended by a medically } \\
\text { trained provider }\end{array}$ & $\begin{array}{l}\text { Out-of-facility deliveries } \\
\text { attended by a TBA, } \\
\text { trained TBA, relative, } \\
\text { no-one or other. }\end{array}$ & $\begin{array}{l}\text { Private healthcare } \\
\text { facilities }\end{array}$ \\
\hline Ethiopia & $\begin{array}{l}\text { Specialist hospitals, } \\
\text { General hospitals, } \\
\text { Primary hospitals }\end{array}$ & Health centres & $\begin{array}{l}\text { Deliveries attended } \\
\text { by a HEW (health post } \\
\text { or out of facility) }\end{array}$ & $\begin{array}{l}\text { Out-of-facility deliveries } \\
\text { attended by a TBA, } \\
\text { trained TBA, relative, } \\
\text { no-one or other. }\end{array}$ & $\begin{array}{l}\text { Private healthcare } \\
\text { facilities }\end{array}$ \\
\hline \multicolumn{6}{|c|}{ Uterotonic used for PPH prevention (non-operative deliveries) in status quo } \\
\hline Bangladesh & Injectable oxytocin & Injectable oxytocin & $\begin{array}{l}\text { Injectable oxytocin } \\
\text { or misoprostol }\end{array}$ & Misoprostol & Injectable oxytocin \\
\hline Ethiopia & Injectable oxytocin & Injectable oxytocin & Misoprostol & None & Injectable oxytocin \\
\hline \multicolumn{6}{|c|}{ Uterotonic used for PPH prevention (non-operative deliveries) in intervention scenario ${ }^{a}$} \\
\hline Bangladesh & Inhaled oxytocin & Inhaled oxytocin & Inhaled oxytocin & Inhaled oxytocin & Injectable oxytocin \\
\hline Ethiopia & Inhaled oxytocin & Inhaled oxytocin & Inhaled oxytocin & None & Injectable oxytocin \\
\hline
\end{tabular}

HEW health extension worker, $P P H$ postpartum haemorrhage, TBA traditional birth attendant

an intervention scenario, injectable oxytocin continues to be used for operative deliveries, while inhaled oxytocin is used for non-operative deliveries in settings where roll out is modelled. See appendix (Additional file 1) for estimates of operative delivery rates in each delivery setting

\section{Current use of uterotonics}

Current use (coverage) of injectable oxytocin and misoprostol at each level of facility was drawn from health facility reviews (Table 4) $[15,17,42]$. For out-of-facility births, we assume only misoprostol is available for a subset of deliveries. In Bangladesh, current estimates of misoprostol coverage at out-of-facility deliveries reflect an incomplete stage of program roll out. To estimate the coverage that may be achieved at 'full scale', we modelled misoprostol use at $50 \%$ of the coverage level found in intervention studies in rural Bangladesh (83.7\%), varying this scaling factor from 25 to $75 \%$ in sensitivity analyses [41]. In Ethiopia, we assume $84 \%$ of women with HEW-assisted deliveries receive misoprostol, based on health facility survey data of the availability of various reproductive health medicines at health posts [42]. This was varied in a sensitivity analysis to account for the uncertainty surrounding this assumption. We assume that women who delivered themselves or with another type of attendant do not receive misoprostol.

\section{Rollout of IHO}

For the intervention scenarios, we modelled a direct substitution of current uterotonics with IHO for nonoperative deliveries, assuming that coverage of $\mathrm{IHO}$ would be equivalent to current uterotonics. We assume
IHO would not be used for caesarean deliveries, and thus, there is no effect of the intervention on caesarean section deliveries.

\section{Cost}

Three categories of costs were included in the analysis: intervention up-front costs (advocacy and training), ongoing PPH prevention costs (commodity costs, wastage and disposal), and PPH treatment costs (Table 5). Further detail is available in the appendix (Additional file 1).

We considered the cost of advocacy required for sensitisation of key stakeholders at all levels (national policy makers, sub-national program managers and community members) through workshops and meetings. Training costs included the costs of preparative activities (curriculum development and training of trainers) in addition to the in-service training of healthcare providers (upfront and refresher trainings). In-service training costs were applied to the number of facilities where introduction of the drug was modelled. Training costs were drawn from a combination of literature sources and insights from experts in each country.

Commodity costs include the uterotonic (injectable oxytocin, misoprostol and $\mathrm{IHO}$ ) and the syringe and needle needed for administration of injectable oxytocin. Dosage of each drug administered was modelled to be 
Table 3 Input parameters used to model health outcomes

\begin{tabular}{|c|c|c|c|c|}
\hline & \multicolumn{2}{|c|}{ Bangladesh } & \multicolumn{2}{|l|}{ Ethiopia } \\
\hline & Value & Source & Value & Source \\
\hline Number of women of reproductive age (15-49) ('000) & $44,998^{\mathrm{a}}$ & UN data 2017 [34] & $24,150^{\mathrm{a}}$ & UN data 2017 [34] \\
\hline Fertility rate of women of reproductive age (15-49) & $73^{\mathrm{a}}$ & DHS 2015 [35] & $141^{\mathrm{a}}$ & DHS 2016 [36] \\
\hline Maternal mortality ratio ${ }^{b}$ & $205^{\mathrm{a}}$ & BMMS 2016 [13] & 412 & EmONC assessment 2016 [17] \\
\hline Maternal deaths due to PPH & $27 \%{ }^{a}$ & BMMS 2016 [13] & $31 \%$ & EmONC assessment 2016 [17] \\
\hline \multicolumn{5}{|l|}{ Child survival rate (to age of 12 months) } \\
\hline If mother survives & $92.4 \%$ & Ronsmans et al. 2010 [37] & $95.6 \%$ & Moucheraud et al. 2015 [38] \\
\hline If mother dies within 42 days of childbirth & $29.6 \%$ & Ronsmans et al. 2010 [37] & $18.75 \%$ & Moucheraud et al. 2015 [38] \\
\hline \multicolumn{5}{|l|}{ Incidence of PPH without preventative uterotonics } \\
\hline Mild & $11.3 \%$ & Gallos et al. 2018 [8] & $11.3 \%$ & Gallos et al. 2018 [8] \\
\hline Severe & $5.9 \%$ & Gallos et al. 2018 [8] & $5.9 \%$ & Gallos et al. 2018 [8] \\
\hline \multicolumn{5}{|l|}{ Risk ratio of mild PPH with uterotonics for prevention } \\
\hline Injectable oxytocin & 0.61 & Gallos et al. 2018 [8] & 0.61 & Gallos et al. 2018 [8] \\
\hline Misoprostol & 0.75 & Gallos et al. 2018 [8] & 0.75 & Gallos et al. 2018 [8] \\
\hline Inhaled oxytocin & 0.61 & Assumption & 0.61 & Assumption \\
\hline \multicolumn{5}{|l|}{ Risk ratio of severe $\mathrm{PPH}$ with uterotonics for prevention } \\
\hline Injectable oxytocin & 0.61 & Gallos et al. 2018 [8] & 0.61 & Gallos et al. 2018 [8] \\
\hline Misoprostol & 0.73 & Gallos et al. 2018 [8] & 0.73 & Gallos et al. 2018 [8] \\
\hline Inhaled oxytocin & 0.61 & Assumption & 0.61 & Assumption \\
\hline
\end{tabular}

UN United Nations, DHS Demographic and Health Survey, BMMS Bangladesh Maternal Mortality Survey, EmONC Emergency Obstetric and Neonatal Care, PPH postpartum haemorrhage

${ }^{a}$ Age-specific values used (5-year brackets)

${ }^{b}$ Deaths per 100,000 live births

consistent with standard guidelines of practice in each country. Public and private sector prices were included and applied to the appropriate delivery setting. The final price of IHO is yet to be determined. In the base case analysis, we model the price of IHO at US\$ 0.50. A sensitivity analysis was conducted to model additional price points of $\$ 0.25$ and $\$ 1$.

Disposal costs were based on required method of disposal: syringes to be incinerated and inhalers to be disposed of without incineration. The cost of waste disposal for injectable and inhaled oxytocin was estimated from the disposal costs of a vaccination program in Bangladesh [43], which reports on incineration and non-incineration costs associated with disposal of cholera vaccine vials. The cost of disposal associated with misoprostol was considered negligible.

Wastage costs were included to account for drugs compromised by heat, expiry date, breakage and wear and tear. Wastage rates for injectable oxytocin and misoprostol were modelled at $5 \%$ based on studies of medical ampoule wastage rates [44]. For inhaled oxytocin, a higher wastage rate (7\%) was assumed based on expert opinion that the inhaler may be discarded at a slightly higher rate than the oxytocin ampoule due incorrect use of the device (Table 5).

Finally, we included the location-specific cost of PPH treatment. We used a micro-costing approach to model the costs of treating mild or severe $\mathrm{PPH}$ in a public or a private facility drawn from a combination of literature sources and in-country consultations with relevant informants. Interviews were conducted in September 2017 (Bangladesh) and November 2017 (Ethiopia) with senior Ministry of Health personnel, hospital administrators and clinicians providing obstetric care at private and public hospitals. Costs modelled include direct medical and non-medical expenditures (e.g. food for the mother and accompanying relatives, transport, tips, accommodation for accompanying relatives) [31-33]. We did not consider indirect costs associated with lost productivity. Treatment costs were varied in sensitivity analyses.

To determine the number of women treated, we assumed $90 \%$ of women experiencing $\mathrm{PPH}$ after giving birth in a facility will receive treatment there. We drew from the literature and country surveys to estimate the number of women seeking care after a home birth in each country. All care-seeking estimates were varied in sensitivity analyses.

\section{Sensitivity analyses}

Several sensitivity analyses were carried out to account for the uncertainty in the model input parameters and to test the impact of different scenarios or structural aspects of the model on outcomes. 


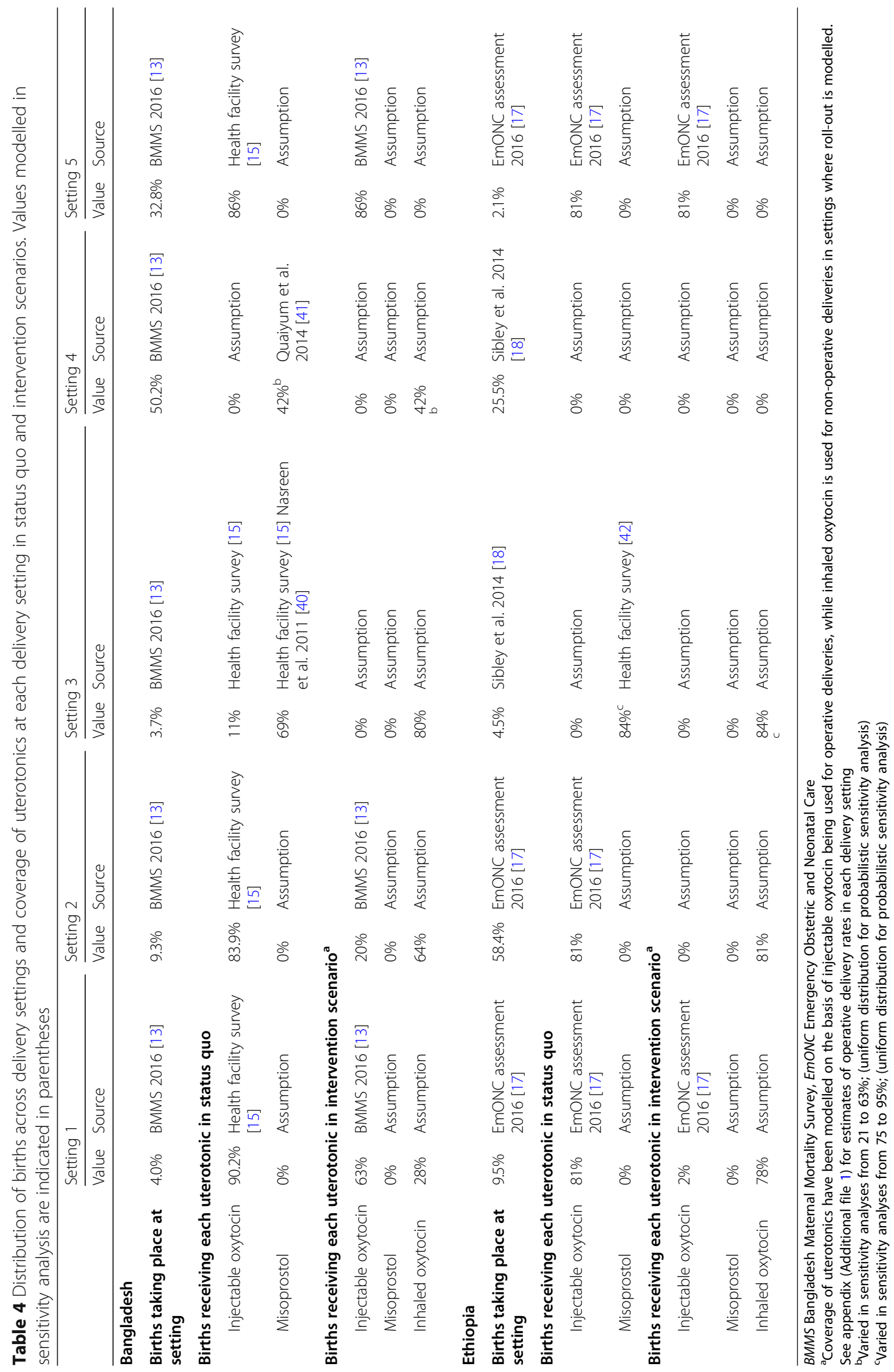




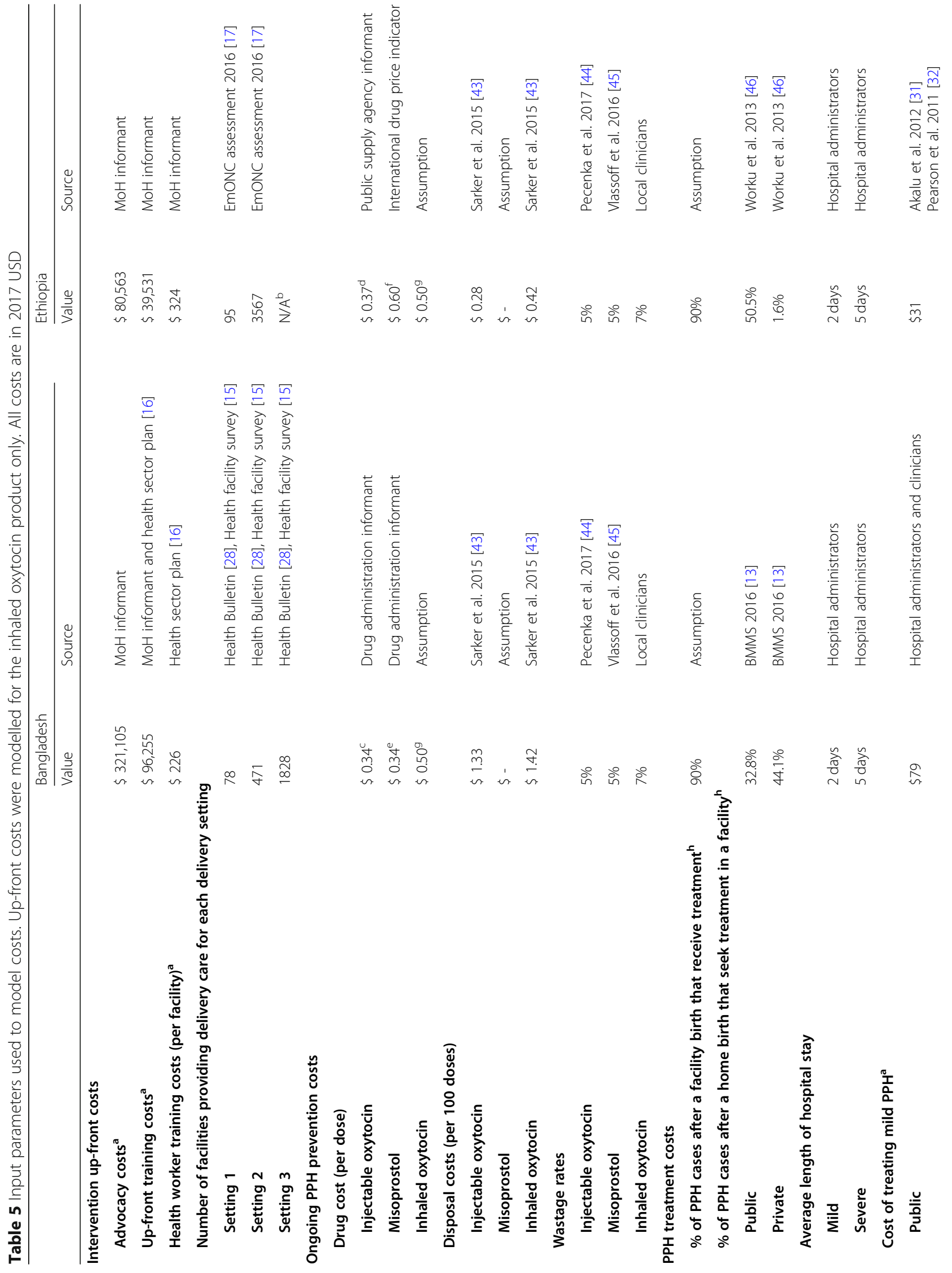




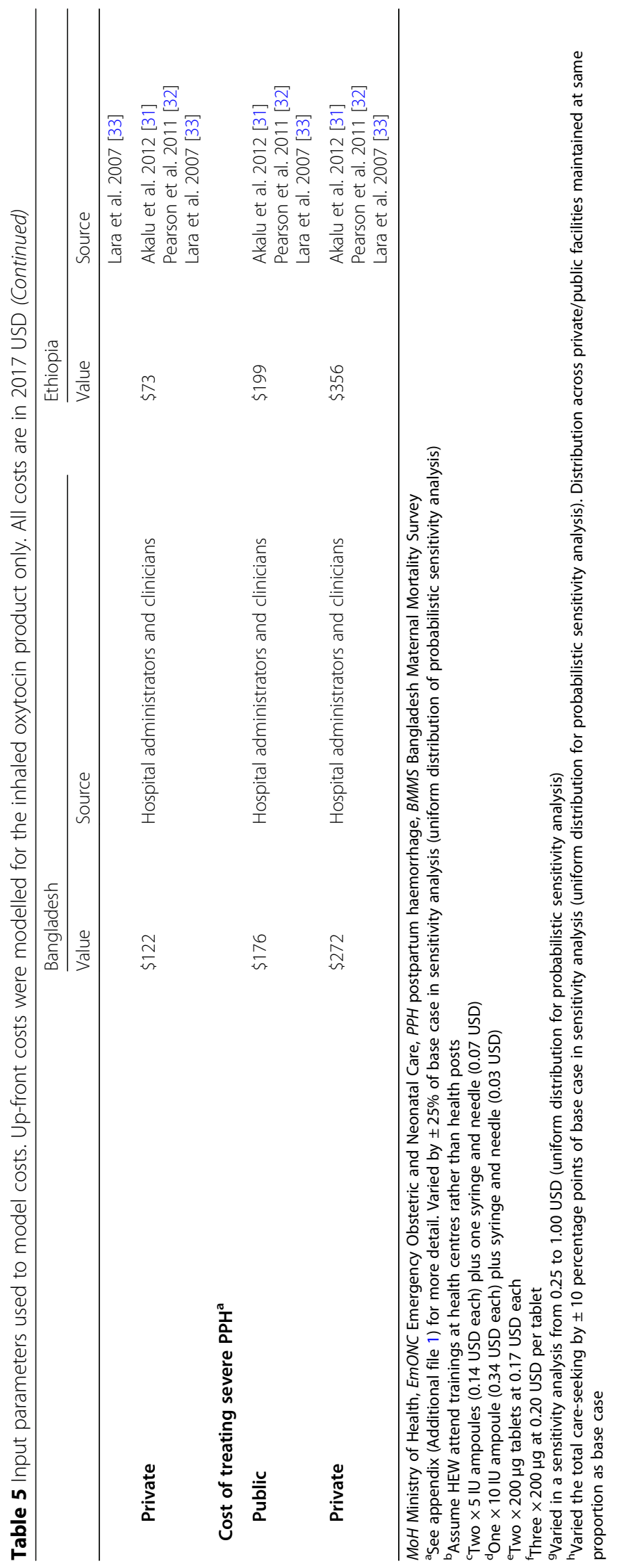




\section{Deterministic sensitivity analyses}

The final cost of IHO is currently unknown, so this parameter was varied from $\$ 0.25$ to $\$ 1.00$ in both countries. A threshold analysis was conducted to determine the price threshold for cost-effectiveness of the product. Given up-front intervention costs were found to vary substantially across both countries, we modelled an uncertainty range of $\pm 25 \%$ of all program introduction costs, including both advocacy and training costs. The proportion of women seeking care following a PPH was varied by \pm 10 percentage points for all births in and out of a facility. Treatment costs for non-severe and severe $\mathrm{PPH}$ in a health facility were varied by $\pm 25 \%$ of base case estimates.

\section{Scenario analyses}

We varied the coverage of misoprostol (in status quo) and IHO (in intervention scenario) for home births with an unskilled attendant in Bangladesh and with HEW in Ethiopia. For Bangladesh, we modelled a range from 25 to $75 \%$ of the misoprostol coverage level found in intervention studies [38]. For Ethiopia, we model coverage of uterotonics with HEW to range from 75 to $95 \%$. As previously explained, we also varied the proportion of deliveries in facilities in both countries.

\section{Structural uncertainty analyses}

We present results with and without child health outcomes included. The number of child deaths was estimated based on country-specific longitudinal studies which report on the association between maternal death and child survival (Table 3). The number of child life years lost was estimated based on countryspecific life expectancy at birth [47]. A 3\% discount rate was applied to number of life years lost, which was varied, along with the $3 \%$ discount rate applied to maternal life years lost, from 0 to $6 \%$ as part of a second structural sensitivity analysis.

We also present results with and without the up-front introduction costs (advocacy and training), to provide an indication of the cost-effectiveness of IHO after several years, when training of health workers is included within the routine curricula and only recurrent costs become relevant.

\section{Probabilistic sensitivity analysis}

Finally, we conducted a probabilistic sensitivity analysis to evaluate the joint uncertainty of input parameters simultaneously. We ran 10,000 simulations, varying all key parameters described above in the deterministic sensitivity analyses as well as those varied in the scenario analyses, using uniform distributions for all parameters. Probabilistic sensitivity analyses were run separately for each of the structural analyses specified above apart from discount rate, which was kept at 3\% across all probabilistic sensitivity analyses. Results were presented as cost-effectiveness acceptability curves.

\section{Results}

In the base case analysis, IHO introduction would avert over 18,500 PPH cases in Bangladesh annually, while just over $3000 \mathrm{PPH}$ cases would be avoided in Ethiopia (Table 6). Our model predicts an estimated $76 \mathrm{PPH}-$ related maternal deaths would be averted in Bangladesh annually, and 30 deaths averted in Ethiopia each year, a reduction of $4.2 \%$ and $0.7 \%$ of the current number of $\mathrm{PPH}$-related deaths, respectively. These results translate into nearly 2000 maternal life years saved over the women's remaining lifetime from a 1-year IHO program in Bangladesh and 767 maternal life years saved in Ethiopia (Table 6).

In terms of costs, the current spending on uterotonics for $\mathrm{PPH}$ prevention and the costs of introducing an IHO program are much lower than the estimated costs of $\mathrm{PPH}$ treatment (Table 7). In Bangladesh, the cost savings from reduced spending on treatment due to $\mathrm{IHO}$ introduction exceed the additional cost of IHO introduction. As a result, IHO was found to be cost-saving compared to the status quo in Bangladesh, when replacing the current use of uterotonics in public facilities and home births with and without skilled attendants. A threshold analysis indicated that IHO ceases to be a cost-saving intervention when the price of the product exceeds $\$ 1.15$ (USD); however, it remains highly cost-effective up to a price of $\$ 1.90$ (at which point the ICER $=25 \%$ of the GDP per capita).

In Ethiopia, IHO introduction had an ICER between two and three times the GDP per capita, indicating it is unlikely to be a cost-effective strategy. A price of $\$ 0.08$ would be required for IHO to be considered a costeffective intervention in Ethiopia based on a $1 \times$ GDP per capita threshold. Excluding up-front introduction costs related to advocacy and training, IHO had an ICER of under $25 \%$ per capita GDP in Ethiopia, indicating a recurring program is likely to become cost-effective after several years of implementation, once IHO has become wellintegrated into the health personnel training curricula.

\section{Sensitivity analysis}

See Figs. 2 and 3 for the one-way sensitivity analyses results for Bangladesh and Ethiopia, respectively, with results presented both with and without child health outcomes included. IHO introduction remained costsaving in Bangladesh across all sensitivity analyses conducted, with one exception: assuming less use of uterotonics (misoprostol in the status quo, IHO in the intervention scenario) at home births without a trained provider present. At the lower bound value modelled for 
Table 6 Estimated maternal and child health benefits of a 1-year inhaled oxytocin introduction program over a lifetime horizon with a $3 \%$ discount rate

\begin{tabular}{|c|c|c|c|c|c|c|}
\hline & \multicolumn{3}{|l|}{ Bangladesh } & \multicolumn{3}{|l|}{ Ethiopia } \\
\hline & Status quo & Intervention & Averted & Status quo & Intervention & Avertec \\
\hline PPH cases, non-severe & 291,978 & 278,813 & 13,165 & 297,868 & 295,672 & 2197 \\
\hline PPH cases, severe & 150,947 & 145,467 & 5479 & 155,178 & 154,264 & 914 \\
\hline Maternal deaths & 1806 & 1730 & 76 & 4418 & 4388 & 30 \\
\hline Maternal life years lost & 46,429 & 44,475 & 1954 & 111,767 & 111,000 & 767 \\
\hline Child deaths & 1135 & 1088 & 48 & 3394 & 3371 & 23 \\
\hline Child life years lost & 33,480 & 32,071 & 1409 & 97,284 & 96,616 & 668 \\
\hline
\end{tabular}

$P P H$ postpartum haemorrhage

this parameter ( $21 \%$ coverage), the ICER rose to $\$ 47$ per maternal life year saved, still highly cost-effective at 3\% of GDP/capita.

In Ethiopia, the most favourable results were obtained at $0 \%$ discount rate (ICER of $\$ 990$ per maternal life year saved) or at a price of $\$ 0.25$ for IHO (ICER of $\$ 1187$ per maternal life year saved). In both cases, with the ICER still above 1.3 times the per capita GDP in Ethiopia, IHO is still unlikely to be cost-effective based on a percapita GDP threshold. Findings were most sensitive to the price of IHO and the choice of discount rate applied to the future live years saved from a maternal (and child) death. The ICER of IHO introduction in Ethiopia was only found to have an ICER of less than one GPD per capita under a subset of "combined" favourable scenarios, such as when including child health gains in addition to modelling a lower cost of IHO at $\$ 0.25$, or when including child health gains and modelling a $0 \%$ discount rate. From an on-going program perspective, IHO would likely be cost-effective when the advocacy and training introduction costs were excluded and even cost-saving when these program introduction costs were excluded and IHO was modelled at $\$ 0.25$ per dose. Figure 4 shows the probability of IHO being cost-effective in Ethiopia across a range of willingness-to-pay thresholds tied to Ethiopia's GDP per capita. Findings from the probabilistic sensitivity analysis (Fig. 4) show that considering maternal outcomes only, IHO has only a $10 \%$

Table 7 Estimated costs and cost-effectiveness ratios of inhaled oxytocin introduction in each setting from a societal perspective and over a lifetime horizon, 3\% discount rate

\begin{tabular}{|c|c|c|c|c|c|c|}
\hline & \multicolumn{3}{|l|}{ Bangladesh } & \multicolumn{3}{|l|}{ Ethiopia } \\
\hline & Status quo & Intervention & Incremental & Status quo & Intervention & Incremental \\
\hline \multicolumn{7}{|l|}{ Costs, $\$ 000$} \\
\hline Intervention start-up costs ${ }^{\mathrm{a}}$ & & 955 & 955 & & 1308 & 1308 \\
\hline On-going PPH prevention ${ }^{\mathrm{b}}$ & 783 & 985 & 202 & 840 & 1108 & 268 \\
\hline PPH treatment & 52,479 & 50,606 & -1873 & 31,141 & 31,007 & -134 \\
\hline Total costs & 53,262 & 52,546 & -716 & 31,981 & 33,423 & 1443 \\
\hline \multicolumn{7}{|l|}{ ICERs } \\
\hline$\$$ per PPH case averted & & Cost-saving & & & 464 & \\
\hline \$ per maternal death averted & & Cost-saving & & & 47,557 & \\
\hline$\$$ per maternal life year saved & & Cost-saving & & & 1880 & \\
\hline \$ per maternal and child life year saved & & Cost-saving & & & 1005 & \\
\hline \multicolumn{7}{|l|}{ ICERs (ongoing costs only) } \\
\hline \$ per PPH case averted & & Cost-saving & & & 43 & \\
\hline$\$$ per maternal death averted & & Cost-saving & & & 4435 & \\
\hline$\$$ per maternal life year saved & & Cost-saving & & & 175 & \\
\hline$\$$ per maternal and child life year saved & & Cost-saving & & & 94 & \\
\hline
\end{tabular}

Societal costs include public and private sector costs, and household medical and direct non-medical out of pocket costs in public and private sectors ICER incremental cost-effectiveness ratio, $P P H$ postpartum haemorrhage

${ }^{\text {a }}$ Training and advocacy costs

${ }^{\mathrm{b} C o m m o d i t y}$ (uterotonics), disposal and wastage costs 


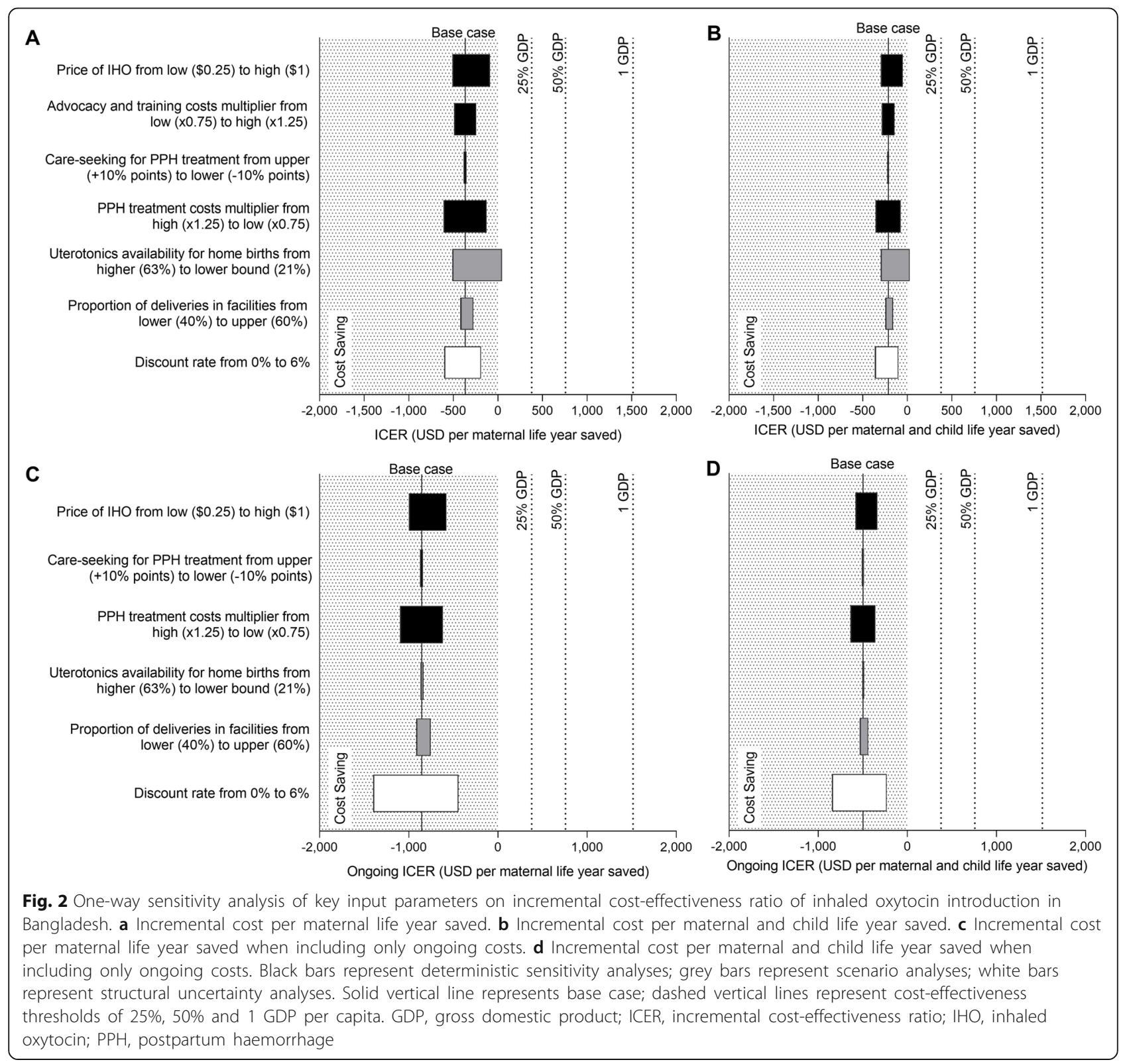

probability of cost-effectiveness in Ethiopia at a willingness to pay threshold of twice GDP per capita. Considering both maternal and child health outcomes, IHO has less than a $10 \%$ probability of being cost-effective at a willingness to pay threshold of GDP per capita. From an on-going program perspective, IHO is over $60 \%$ likely to be cost-effective based on a one times GDP per capita threshold.

\section{Discussion}

This is the first study to comprehensively model the cost-effectiveness of an inhaled oxytocin product for the prevention of PPH in Bangladesh and Ethiopia. In both countries, introduction of inhaled oxytocin to replace injectable oxytocin and misoprostol for PPH prevention was predicted to result in a modest decrease in the maternal deaths and a reduction in the number of $\mathrm{PPH}$ cases. No health outcome gains were associated with replacement of injectable oxytocin with the inhaled product at higher level health facilities, as these two oxytocin formulations were modelled to have equivalent efficacy. However, this does not take into consideration the likelihood that compromised cold temperature maintenance during transport and storage may have led to degradation of injectable oxytocin. Several studies have indicated that the quality of oxytocin product available in 


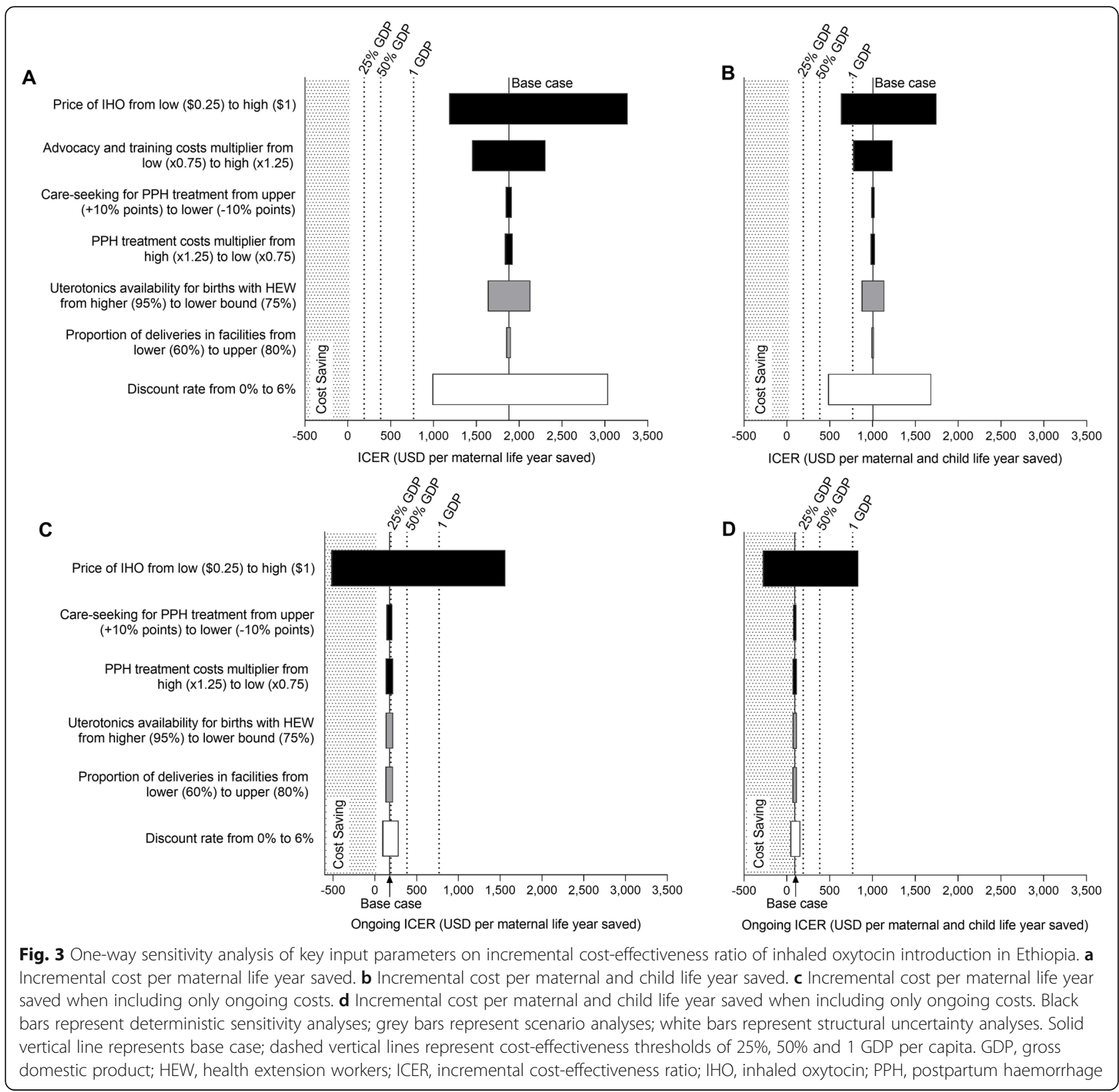

LMICs is compromised-in part due to inadequate cold chain storage [4, 48, 49]. A 2016 systematic review found an average of $22.3 \%$ and $57.5 \%$ of oxytocin ampoules collected from Asia and Africa respectively contained below the specified content of oxytocin [4]. However, there are no published studies investigating the impact of poor quality oxytocin on clinical outcomes, and research in this area is challenged by ethical considerations. Thus, while it is not possible to reliably model the health impact associated with replacement of injectable oxytocin with a heat stable product, it can be assumed that health outcomes could be improved to a greater extent that predicted by this model.
Consequently, all health gains were accrued through the replacement of misoprostol with inhaled oxytocin, the latter of which has a greater efficacy for the prevention of PPH. In Bangladesh, this represents a large number of deliveries, encompassing a proportion of home births in addition to deliveries in a subset of primary health facilities that are currently using a mix of oxytocin and misoprostol. In contrast, even small health gains were not seen in facility settings in Ethiopia due to the assumption that misoprostol is not used in lower level facilities. In addition, only a small proportion of deliveries are attended by HEWs (who are assumed to use misoprostol for prevention of $\mathrm{PPH}$ ), and as such, switching to IHO 

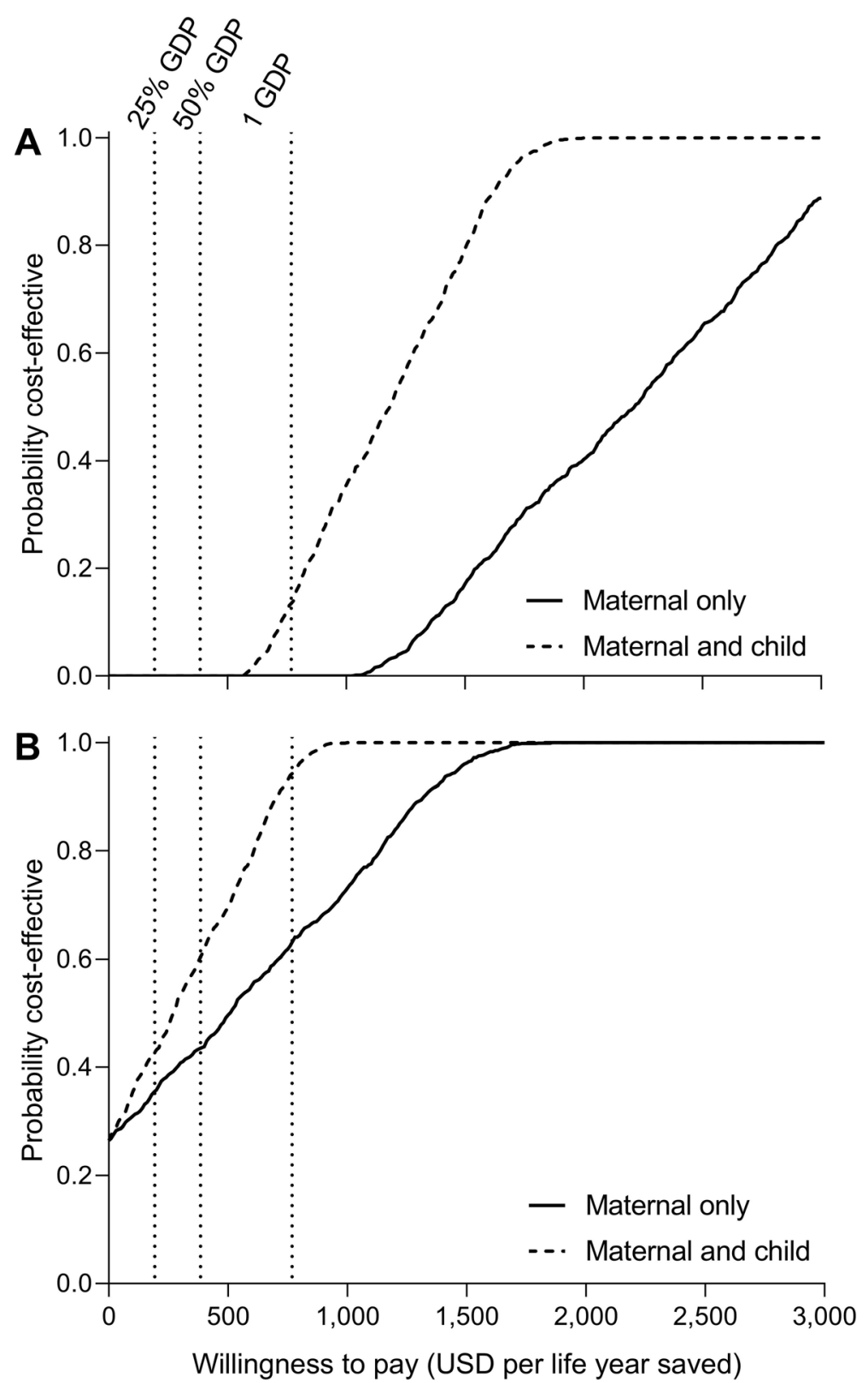

Fig. 4 Cost-effectiveness acceptability frontier showing the probability that inhaled oxytocin is cost-effective for different willingness to pay thresholds in Ethiopia. Willingness to pay is shown in terms of USD per maternal life years saved (solid line) or maternal and child life years saved (dashed line). a The base case analysis, where all implementation costs are included. b Only ongoing costs are included in the analysis. A 3\% discount rate was used. Dashed vertical lines represent 25\%, 50\% and 1 GDP per capita. GDP, gross domestic product

results in very small health gains overall in Ethiopia as compared to Bangladesh where wider access to IHO was modelled through an advanced community distribution approach.

In Bangladesh, adoption of the inhaled oxytocin product was predicted to be a cost saving, a finding driven by reduced spending on PPH treatment that is made possible by averting cases of $\mathrm{PPH}$. These findings were robust to different sensitivity analyses carried out including those affecting total spending on PPH treatment (per case cost of $\mathrm{PPH}$ and percentage of cases seeking treatment).

In Ethiopia, the full program of IHO introduction was predicted to cost greater than double the GDP per capital per maternal life year saved and thus is unlikely to be considered a cost-effective intervention. When including child deaths likely to be averted, IHO introduction was still found to have a cost-effectiveness ratio of greater than Ethiopia's GDP per capita. Across all sensitivity analyses carried out, the intervention was only 
found to have an ICER of less than one GDP per capita under a subset of "combined" favourable scenarios (consideration of both maternal and child health outcomes, coupled with a reduced discount rate for future benefits or lower price of IHO). The unfavourable costeffectiveness ratio for inhaled oxytocin in Ethiopia is largely driven by the high up-front costs associated with product introduction. When considering a scenario several years in the future, when IHO has been fully integrated into the health system, the ICER of the product is less than a quarter of the country's GDP per capita. Thus on an ongoing basis, the product could be considered a cost-effective intervention for Ethiopia.

The up-front costs of training in Ethiopia were predicted by this model to be almost double those in Bangladesh. The number of facilities where training is required to be administered in Ethiopia exceeds Bangladesh by over 1200 , contributing to the overall high costs of health worker training in Ethiopia. The mechanisms employed to administer up-front training for a new product, particularly in vast geographies with a large number of health facilities, should be given careful consideration to maximise the potential for products to deliver cost-effective health impacts. Cost-effective strategies will likely entail 'bundling' training for multiple products and services together, such that costs can be diffused across a wider set of health impacts.

There are considerable differences in the demographic and policy contexts between Bangladesh and Ethiopia that allow for translation of results to a variety of other countries. In Bangladesh, rates of out-of-facility deliveries are high $(>50 \%)$ and the policy environment will likely support roll out of IHO to these settings. Together, these attributes are a significant driving force for the cost-saving that is predicted, as a large proportion of births gain access to a uterotonic with gold standard efficacy against PPH. Similar cost-effectiveness ratios may be expected in other high-burden countries such as Nigeria, Afghanistan and Pakistan, where rates of out-offacility deliveries and uterotonic policy contexts are similar to Bangladesh. In contrast, in Ethiopia, relatively few births take place outside of facility settings, and policy support for availability of uterotonics in community settings is limited to births attended by a skilled provider (representing a small portion of births). Thus, the costeffective ratios predicted for Ethiopia may be similar to those expected in countries such as India, Indonesia, Kenya and the Democratic Republic of Congo.

There are several important strengths and limitations to this modelling exercise that warrant further discussion. Our decision analytic model does not capture other maternal complications including antenatal haemorrhage, or quantify the morbidity impacts of PPH due to anaemia. In addition, we do not model the costs of side effects associated with uterotonics, which have been previously estimated to significantly improve the costeffectiveness of oxytocin compared to misoprostol due to the side effect profile associated with the latter, which includes shivering, fever, nausea and vomiting [50]. These simplifications are likely to underestimate the true health benefits of IHO and thus represent a conservative simplification.

Cold chain costs were not modelled as storage costs were thought to apply equally to both scenarios given the continued requirement for cold chain systems (for injectable oxytocin required for operative delivery as well as other temperature sensitive drugs) despite introduction of inhaled oxytocin. Further, the lack of reliable costing by volume data for refrigerated and nonrefrigerated transport limited credible estimations of cold chain supply costs. Omission of cold chain costs from the model may lead to an underestimation of the cost-effectiveness of the IHO product. However, the decision not to include this cost item is supported by previous studies that have shown that negligible cold chain savings are associated with the replacement of a subset of temperature-sensitive medicines with heat-stable formulations [51, 52].

We model a 1-year program of IHO introduction, applying an assumption that all costs are incurred and maximal coverage is reached during this period. We acknowledge this to be a simplification, as realistically such a program may need greater than 12 months to scale-up and thus costs are likely to be incurred over multiple years, with health gains increasing to reach our estimates over this time. We also show results of an IHO program running at scale and fully integrated into the existing maternal health program, by modelling the costs and cost-effectiveness of the intervention with and without the start-up training costs.

A strength of this analysis is that it gives consideration to both maternal and child health outcomes. A recent systematic review of strategies to improve maternal or newborn health in LMICs shows that most costeffectiveness analyses report on either maternal or child health outcomes, but rarely both [53]. This approach underestimates of the true magnitude of effect of a maternal health intervention considering that child mortality associated with a maternal death is consistently high across all reported studies [37, 38, 54, 55].

The model assumes that IHO has equivalent efficacy to an injection of oxytocin based on research showing that these two administration routes give rise to comparable systemic concentrations of oxytocin over time in healthy volunteers [11]. The potential for inhaled delivery of peptides to match efficacy profiles of parenteral routes of administration has been demonstrated with inhaled insulin [56]. However, the efficacy of IHO in 
comparison to an intramuscular injection of oxytocin is yet to be demonstrated and as such the results of this economic analysis may require revision pending the results of large-scale efficacy trials in postpartum women.

The model assumes that there is no difference in the feasibility and acceptability of administering IHO to women immediately after childbirth compared to the uterotonics used in the status quo (injectable oxytocin and sublingual misoprostol). Qualitative research conducted in Myanmar supports this assumption, with healthcare providers and community members suggesting that IHO is likely to be largely acceptable and feasible to use [57]. Yet there are potential implementation challenges of IHO particularly in settings where a skilled birth attendant is managing the labour and delivery without any assistance, and relying on a mother or other family member being able to follow instructions for IHO administration at the time of birth. While this may pose a challenge to effective administration of a full therapeutic dose of IHO, the model includes costs for community sensitisation activities to improve the likelihood of successful administration. Nevertheless, local feasibility and acceptability studies in each context would be important undertakings alongside product introduction.

\section{Conclusions}

In summary, this work provides valuable insights into the potential cost-effectiveness of IHO in different health system contexts. In settings like Bangladesh, where a significant number of women currently lack access to oxytocin for the prevention of $\mathrm{PPH}$ at the time of birth, IHO is a cost-saving intervention, as health impacts are accompanied by a substantial reduction in spending on PPH treatment. In the Ethiopian context, the product may not be considered a cost-effective intervention until the product is fully integrated into the health system and up-front introduction costs are no longer incurred. For both country contexts, our findings likely represent an underestimate of the health impacts and cost-effectiveness of IHO, given that it has not been possible to model the impact of inadequate cold storage of injectable oxytocin in our estimate of health outcomes in the status quo. Further research to understand the true cost of poor quality oxytocin would aid in the evaluation of the cost-effectiveness of IHO and other heat stable uterotonics.

\section{Supplementary information}

Supplementary information accompanies this paper at https://doi.org/10. 1186/s12916-020-01658-y.

Additional file 1: Supplemental appendix. This appendix provides further detail of model inputs relating to rates of caesarean section delivery, start-up costs for $\mathrm{HO}$ introduction and costs of PPH treatment.

\section{Abbreviations}

DHS: Demographic and health survey; GDP: Gross domestic product: HEW: Health extension worker; ICER: Incremental cost-effectiveness ratio; IHO: Inhaled oxytocin; LMIC: Low- and middle-income countries;

MMR: Maternal mortality ratio; PPH: Postpartum haemorrhage;

SDG: Sustainable Development Goal; USD: United States dollar; WHO: World Health Organization

\section{Acknowledgements}

Authors gratefully acknowledge the contribution of Antenneh Asefa Mekonnen for his assistance with data collection in Ethiopia and Ajay Mahal for his input into model design.

\section{Authors' contributions}

VLO, PL, MM and AM conceived and designed the study; NC, MEH, AM, VLO and $A B$ built the model and did the analysis; $M E H$ and $A M$ provided the country data; AM and PL helped to validate and interpret the models; NC wrote first draft of manuscript, and all co-authors contributed to the final draft. All authors read and approved the final manuscript.

\section{Funding}

This work was made possible through the generous support of the Saving Lives at Birth partners: the United States Agency for International Development, the Government of Norway, the Bill \& Melinda Gates Foundation, Grand Challenges Canada, the UK Government and the Korea International Cooperation Agency (Grant \#: AID-OAA-F-17-00012). The funders had no role in the design, conduct, analysis or writing up of the study. All authors had full access to the model and input data and jointly took the decision to submit for publication.

\section{Availability of data and materials}

The model developed and used in this study is available from the corresponding author on reasonable request.

\section{Ethics approval and consent to participate}

Ethical clearance for the primary and secondary data collection required to inform development of the model was obtained from the Human Research Ethics Committee of the University of Melbourne (Ethics ID: 1749798.1).

\section{Consent for publication}

Not applicable.

\section{Competing interests}

VLO, PL and MPM are part of a product development team at Monash University, which is developing an inhaled heat stable oxytocin product for the prevention of PPH in resource-poor settings.

MPM is the co-inventor of a worldwide patent application 'Method and Formulation for Inhalation' (WO 2013/016754) that covers the delivery of biologically active agents (including oxytocin) in the form of dry powders for inhalation. The authors have no commercial interest in the outcomes of this study or the introduction of the inhaled oxytocin product in LMICs.

All other authors declare no other competing interests.

\section{Author details}

${ }^{1}$ Centre for Health Policy \& Global Burden of Disease Group, School of Population and Global Health, The University of Melbourne, Melbourne, VIC 3010, Australia. ${ }^{2}$ Agency for Clinical Innovation, NSW Ministry of Health, Sydney, NSW 2067, Australia. ${ }^{3}$ Drug Delivery Disposition and Dynamics, Monash Institute of Pharmaceutical Sciences, Monash University, Parkville, VIC 3052, Australia. ${ }^{4}$ Nossal Institute for Global Health, Melbourne School of Population and Global Health, University of Melbourne, Melbourne, VIC, Australia.

Received: 27 January 2020 Accepted: 7 June 2020

Published online: 28 July 2020

References

1. Collaborators GBDMM. Global, regional, and national levels of maternal mortality, 1990-2015: a systematic analysis for the Global Burden of Disease Study 2015. Lancet. 2016;388(10053):1775-812. 
2. Alkema L, Chou D, Hogan D, Zhang S, Moller AB, Gemmill A, et al. Global, regional, and national levels and trends in maternal mortality between 1990 and 2015, with scenario-based projections to 2030: a systematic analysis by the UN Maternal Mortality Estimation Inter-Agency Group. Lancet. 2016; 387(10017):462-74

3. World Health Organization. WHO recommendations: uterotonics for the prevention of postpartum haemorrhage. Geneva: World Health Organization; 2018.

4. Torloni MR, Gomes Freitas C, Kartoglu UH, Metin Gulmezoglu A, Widmer M. Quality of oxytocin available in low- and middle-income countries: a systematic review of the literature. BJOG. 2016;123(13):2076-86.

5. Prata N, Passano P, Rowen T, Bell S, Walsh J, Potts M. Where there are (few) skilled birth attendants. J Health Popul Nutr. 2011;29(2):81-91.

6. Adegoke A, Utz B, Msuya SE, van den Broek N. Skilled birth attendants: who is who? A descriptive study of definitions and roles from nine sub Saharan African countries. PLoS One. 2012;7(7):e40220.

7. Olaniran A, Madaj B, Bar-Zev S, van den Broek N. The roles of community health workers who provide maternal and newborn health services: case studies from Africa and Asia. BMJ Glob Health. 2019;4(4):e001388.

8. Gallos ID, Papadopoulou A, Man R, Athanasopoulos N, Tobias A, Price MJ, et al. Uterotonic agents for preventing postpartum haemorrhage: a network meta-analysis. Cochrane Database Syst Rev. 2018;12:CD011689.

9. Zhu C, Estrada M, White J, Lal M. Heat-stable sublingual oxytocin tablets as a potential needle-free approach for preventing postpartum hemorrhage in low-resource settings. Drug Deliv Transl Res. 2018;8(3):853-6.

10. Fabio K, Curley K, Guarneri J, Adamo B, Laurenzi B, Grant M, et al. Heatstable dry powder oxytocin formulations for delivery by oral inhalation. AAPS PharmSciTech. 2015;16(6):1299-306.

11. Fernando D, Siederer S, Singh S, Schneider I, Gupta A, Powell M, et al. Safety, tolerability and pharmacokinetics of single doses of oxytocin administered via an inhaled route in healthy females: randomized, singleblind, phase 1 study. EBioMedicine. 2017;22:249-55.

12. Hobday K, Hulme J, Belton S, Homer CS, Prata N. Community-based misoprostol for the prevention of post-partum haemorrhage: a narrative review of the evidence base, challenges and scale-up. Glob Public Health. 2018;13(8):1081-97.

13. National Institute of Population Research and Training (NIPORT), International Centre for Diarrhoeal Disease Research Banglasdesh (icddr b), MEASURE Evaluation. Bangladesh Maternal Mortality and Health Care Survey 2016: Preliminary Report. Dhaka: NIPORT, icddr,b, MEASURE Evaluation; 2017.

14. Ahmed S, Alam B, Anwar I, Begum T, Huque R, Khan J, et al. Bangladesh Health System Review. New Delhi: Asia Pacific Observatory on Public Health Systems and Policies; 2015. Contract No.: 3.

15. Bangladesh Ministry of Health and Family Welfare. Bangladesh Health Facility Survey 2014. Dhaka, Bangladesh: National Institute of Population Research and Training, Associates for Community and Population Research; 2016.

16. Bangladesh Ministry of Health and Family Welfare. Health, population and nutrition sector development program (2011-2016): program implementation plan. Dhaka: Government of the People's Republic of Bangladesh; 2011.

17. Ethiopian Public Health Institute, Federal Ministry of Health, Columbia University. Ethiopian Emergency Obstetric and Newborn Care (EmONC) Assessment 2016. Addis Ababa: Ethiopian Public Health Institute, Federal Ministry of Health, Columbia University; 2017.

18. Sibley LM, Spangler SA, Barry D, Tesfaye S, Desta BF, Gobezayehu AG. A regional comparison of distribution strategies and women's awareness, receipt, and use of misoprostol to prevent postpartum hemorrhage in rural Amhara and Oromiya regions of Ethiopia. J Midwifery Womens Health. 2014;59(Suppl 1):S73-82.

19. Spangler SA, Gobezayehu AG, Hailemariam TG, Sibley LM. Interpretation of national policy regarding community-based use of misoprostol for postpartum hemorrhage prevention in Ethiopia: a tale of two regions. J Midwifery Womens Health. 2014;59(Suppl 1):S83-90.

20. Wells E, Coeytaux F, Azasi E, Danmusa S, Geressu T, McNally T, et al. Evaluation of different models of access to misoprostol at the community level to improve maternal health outcomes in Ethiopia, Ghana, and Nigeria. Int J Gynaecol Obstet. 2016;133(3):261-5.

21. Hoque ME, Khan JA, Hossain SS, Gazi R, Rashid HA, Koehlmoos TP, et al. A systematic review of economic evaluations of health and health-related interventions in Bangladesh. Cost Eff Resour Alloc. 2011;9:12.
22. McPake B, Edoka I, Witter S, Kielmann K, Taegtmeyer M, Dieleman M, et al. Cost-effectiveness of community-based practitioner programmes in Ethiopia, Indonesia and Kenya. Bull World Health Organ. 2015;93(9):631-9A.

23. Memirie ST, Tolla MT, Desalegn D, Hailemariam M, Norheim OF, Verguet S, et al. A cost-effectiveness analysis of maternal and neonatal health interventions in Ethiopia. Health Policy Plan. 2019;34(4):289-97.

24. World Health Organization. The global prevalence of anaemia in 2011. Geneva: World Health Organization; 2015.

25. World Health Organization. Macroeconomics and health: investing in health for economic development: report of the Commission on Macroeconomics and Health. Geneva: World Health Organization; 2001.

26. Woods B, Revill P, Sculpher M, Claxton K. Country-level cost-effectiveness thresholds: initial estimates and the need for further research. Value Health. 2016;19(8):929-35.

27. Husereau D, Drummond M, Petrou S, Carswell C, Moher D, Greenberg D, et al. Consolidated Health Economic Evaluation Reporting Standards (CHEERS) statement. Value Health. 2013;16(2):e1-5.

28. Directorate General of Health Services. Health Bulletin 2016. Dhaka: Directorate General of Health Services; 2016.

29. Bangladesh Ministry of Health and Family Welfare. Community-based Health Care Operational Plan (2011-2016). Dhaka: Bangladesh Government of the People's Republic of Bangladesh; 2011.

30. Hoque ME, Powell-Jackson T, Dasgupta SK, Chowdhury ME, Koblinsky M. Costs of maternal health-related complications in Bangladesh. J Health Popul Nutr. 2012;30(2):205-12.

31. Akalu T, Guda A, Tamiru M, Mariam DH. Examining out of pocket payments for maternal health in rural Ethiopia: paradox of free health care unaffordability. Ethiop J Health Dev. 2012;26(1):251-7.

32. Pearson L, Gandhi M, Admasu K, Keyes EB. User fees and maternity services in Ethiopia. Int J Gynaecol Obstet. 2011;115(3):310-5.

33. Lara AM, Kandulu J, Chisuwo L, Kashoti A, Mundy C, Bates I. Laboratory costs of a hospital-based blood transfusion service in Malawi. J Clin Pathol. 2007;60(10):1117-20.

34. World Population Prospects: The 2017 Revision [Internet]. United Nations, Department of Economic and Social Affairs, Population Division 2017.

35. National Institute of Population Research and Training, Mitra and Associates, ICF International. Bangladesh Demographic and Health Survey: 2014. Dhaka: Ministry of Health and Family Welfare; 2016.

36. Central Statistics Agency (CSA) and ICF. Demographic and Health Survey 2016: Key Indicators Report. Addis Ababa and Rockville: CSA and ICF; 2016.

37. Ronsmans C, Chowdhury ME, Dasgupta SK, Ahmed A, Koblinsky M. Effect of parent's death on child survival in rural Bangladesh: a cohort study. Lancet. 2010;375(9730):2024-31.

38. Moucheraud C, Worku A, Molla M, Finlay JE, Leaning J, Yamin A. Consequences of maternal mortality on infant and child survival: a 25-year longitudinal analysis in Butajira Ethiopia (1987-2011). Reprod Health. 2015; 12(Suppl 1):S4.

39. Global Health Observatory Data Repository [Internet]. 2016 [cited 6/6/2018]. Available from: http://apps.who.int/gho/data/node.main.687?lang=en.

40. Nasreen H-E, Nahar S, Al Mamun M, Afsana K, Byass P. Oral misoprostol for preventing postpartum haemorrhage in home births in rural Bangladesh: how effective is it? Glob Health Action. 2011;4(1):7017.

41. Quaiyum A, Gazi R, Hossain S, Wirtz A, Saha NC. Feasibility, acceptability, and programme effectiveness of misoprostol for prevention of postpartum haemorrhage in rural Bangladesh: a quasiexperimental study. Int J Reprod Med. 2014;2014:580949.

42. Ethiopian Public Health Institute. Ethiopia service provision assessment plus survey. Addis Ababa: Ethiopian Public Health Institute, Ethiopian Ministry of Health, ICF International; 2014.

43. Sarker AR, Islam Z, Khan IA, Saha A, Chowdhury F, Khan Al, et al. Estimating the cost of cholera-vaccine delivery from the societal point of view: a case of introduction of cholera vaccine in Bangladesh. Vaccine. 2015;33(38):4916-21.

44. Pecenka C, Parashar U, Tate JE, Khan JAM, Groman D, Chacko S, et al. Impact and cost-effectiveness of rotavirus vaccination in Bangladesh. Vaccine. 2017;35(32):3982-7.

45. Vlassoff M, Diallo A, Philbin J, Kost K, Bankole A. Cost-effectiveness of two interventions for the prevention of postpartum hemorrhage in Senegal. Int J Gynaecol Obstet. 2016;133(3):307-11.

46. Worku AG, Yalew AW, Afework MF. Maternal complications and women's behavior in seeking care from skilled providers in North Gondar, Ethiopia. PLoS One. 2013;8(3):e60171. 
47. World Development Indicators: Life expectancy at birth [Internet]. World Bank, 2019 [cited 12/2/2019]. Available from: https://data.worldbank.org/ indicator/SP.DYN.LEOO.IN.

48. Anyakora C, Oni Y, Ezedinachi U, Adekoya A, Ali I, Nwachukwu C, et al. Quality medicines in maternal health: results of oxytocin, misoprostol, magnesium sulfate and calcium gluconate quality audits. BMC Pregnancy Childbirth. 2018;18(1):44.

49. Lambert $P$, Nguyen TH, McEvoy C, Minhas RS, Wright P, Deadman $K$, et al. Quality of oxytocin ampoules available in health care facilities in the Democratic Republic of Congo: an exploratory study in five provinces. J Glob Health. 2018:8(2):020415.

50. Pickering K, Gallos ID, Williams H, Price MJ, Merriel A, Lissauer D, et al. Uterotonic drugs for the prevention of postpartum haemorrhage: a costeffectiveness analysis. Pharmacoecon Open. 2019;3(2):163-76.

51. Karp CL, Lans D, Esparza J, Edson EB, Owen KE, Wilson CB, et al. Evaluating the value proposition for improving vaccine thermostability to increase vaccine impact in low and middle-income countries. Vaccine. 2015;33(30): $3471-9$.

52. Lee BY, Wedlock PT, Haidari LA, Elder K, Potet J, Manring R, et al. Economic impact of thermostable vaccines. Vaccine. 2017;35(23):3135-42.

53. Mangham-Jefferies L, Pitt C, Cousens S, Mills A, Schellenberg J. Costeffectiveness of strategies to improve the utilization and provision of maternal and newborn health care in low-income and lower-middleincome countries: a systematic review. BMC Pregnancy Childbirth. 2014; 14(1):243.

54. Scott S, Kendall L, Gomez P, Howie SR, Zaman SM, Ceesay S, et al. Effect of maternal death on child survival in rural West Africa: 25 years of prospective surveillance data in the Gambia. PLoS One. 2017;12(2):e0172286.

55. Finlay JE, Moucheraud C, Goshev S, Levira F, Mrema S, Canning D, et al. The effects of maternal mortality on infant and child survival in rural Tanzania: a cohort study. Matern Child Health J. 2015;19(11):2393-402.

56. Hollander PA, Blonde L, Rowe R, Mehta AE, Milburn JL, Hershon KS, et al. Efficacy and safety of inhaled insulin (exubera) compared with subcutaneous insulin therapy in patients with type 2 diabetes: results of a 6-month, randomized, comparative trial. Diabetes Care. 2004;27(10):2356-62.

57. Than KK, Oliver V, Mohamed Y, La T, Lambert P, Mclntosh M, et al. Assessing the operational feasibility and acceptability of an inhalable formulation of oxytocin for improving community-based prevention of postpartum haemorrhage in Myanmar: a qualitative inquiry. BMJ Open. 2018;8(10): e022140.

\section{Publisher's Note}

Springer Nature remains neutral with regard to jurisdictional claims in published maps and institutional affiliations.

Ready to submit your research? Choose BMC and benefit from:

- fast, convenient online submission

- thorough peer review by experienced researchers in your field

- rapid publication on acceptance

- support for research data, including large and complex data types

- gold Open Access which fosters wider collaboration and increased citations

- maximum visibility for your research: over $100 \mathrm{M}$ website views per year

At $\mathrm{BMC}$, research is always in progress.

Learn more biomedcentral.com/submissions 